OPEN ACCESS

Edited by:

Chiara Bolego,

University of Padova, Italy

Reviewed by:

Jiiang-Huei Jeng,

National Taiwan University, Taiwan Giustino Orlando, Università degli Studi "G. d'Annunzio"

Chieti - Pescara, Italy

${ }^{*}$ Correspondence: Rui Fang

fangrui19810705@163.com

Specialty section: This article was submitted to Inflammation Pharmacology,

a section of the journal

Frontiers in Pharmacology

Received: 13 April 2018

Accepted: 13 July 2018

Published: 02 August 2018

Citation:

Yang J, Li S, Wang L, Du F, Zhou X, Song $Q$, Zhao J and Fang $R$ (2018)

Ginsenoside Rg3 Attenuates Lipopolysaccharide-Induced Acute Lung Injury via MerTK-Dependent Activation of the PISK/AKT/mTOR

Pathway. Front. Pharmacol. 9:850. doi: 10.3389/fphar.2018.00850

\section{Ginsenoside Rg3 Attenuates Lipopolysaccharide-Induced Acute Lung Injury via MerTK-Dependent Activation of the PI3K/AKT/mTOR Pathway}

\author{
Jing Yang ${ }^{1}$, Senyang Li', Luyao Wang ${ }^{1}$, Fen Du' ${ }^{2}$, Xiaoliu Zhou' ${ }^{1}$, Qiqi Song ${ }^{3}$, \\ Junlong Zhao ${ }^{1}$ and Rui Fang ${ }^{1 *}$
}

' State Key Laboratory of Agricultural Microbiology, College of Veterinary Medicine, Huazhong Agricultural University, Wuhan, China, ${ }^{2}$ Hubei Center for Animal Diseases Control and Prevention, Wuhan, China, ${ }^{3}$ College of Animal Science and Veterinary Medicine, Tianjin Agricultural University, Tianjin, China

Acute lung injury (ALI) is a common clinical disease with high morbidity in both humans and animals. Ginsenoside Rg3, a type of traditional Chinese medicine extracted from ginseng, is widely used to cure many inflammation-related diseases. However, the specific molecular mechanism of the effects of ginsenoside Rg3 on inflammation has rarely been reported. Thus, we established a mouse model of lipopolysaccharide (LPS)-induced ALI to investigate the immune protective effects of ginsenoside Rg3 and explore its molecular mechanism. In wild type (WT) mice, we found that ginsenoside Rg3 treatment significantly mitigated pathological damages and reduced myeloperoxidase (MPO) activity as well as the production of pro-inflammatory

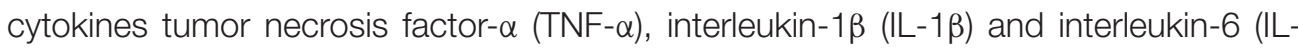
6); furthermore, the production of anti-inflammatory mediators interleukin-10 (IL-10) and transforming growth factor- $\beta$ (TGF- $\beta$ ), polarization of M2 macrophages and expression levels of the phosphorylation of phosphatidylinositol 3-hydroxy kinase (PI3K), protein kinase $B(P K B$, also known as AKT), mammalian target of rapamycin (mTOR) and Mer receptor tyrosine kinase (MerTK) were promoted. However, there were no significant differences with regards to the pathological damage, MPO levels, inflammatory cytokine levels, and protein expression levels of the phosphorylation of PI3K, AKT and mTOR between the LPS treatment group and ginsenoside Rg3 group in MerTK ${ }^{-/-}$mice. Taken together, the present study demonstrated that ginsenoside Rg3 could attenuate LPSinduced ALI by decreasing the levels of pro-inflammatory mediators and increasing the production of anti-inflammatory cytokines. These processes were mediated through MerTK-dependent activation of its downstream the PI3K/AKT/mTOR pathway. These findings identified a new site of the specific anti-inflammatory mechanism of ginsenoside Rg3.

Keywords: acute lung injury, lipopolysaccharide, ginsenoside Rg3, inflammatory, MerTK 


\section{INTRODUCTION}

Acute lung injury (ALI), is a common clinical disease with a high morbidity rate in both humans and animals, which causes injury to the alveolar epithelial cells and pulmonary capillary endothelial cells because of non-cardiogenic factors, and it can further develop into its severe stage, acute respiratory distress syndrome (ARDS) (Ferguson et al., 2005; Niu et al., 2015; Chen et al., 2017). The morbidity rate of ALI is $38.5 \%$, and the high morbidity rate of ARDS even reaches 41.1\% (Rubenfeld et al., 2005). Therefore, it is an urgent need to find more effective medicines to cure ALI, reducing the high morbidity. Lipopolysaccharides (LPSs) are considered to have an important impact on the inflammatory response of ALI and widely used to establish ALI models (Zhu et al., 2017).

In the inflammatory response induced by LPSs, neutrophils and macrophages are recruited, which can eliminate pathogens and produce soluble mediators (Geissmann et al., 2010). Macrophages can be polarized under the stimulation of different microenvironments, and modify their functions between M1 macrophages, which can produce inflammatory mediators and chemokines, and M2 macrophages, which can mediate anti-inflammatory mediators and tissue injury repair (Martinez et al., 2009; Mills, 2012; Sorgi et al., 2017). Mer receptor tyrosine kinase (MerTK) belongs to a member of the Tyro3-Axl-MerTK (TAM) receptor family which shares a common ligand growth arrest-specific protein 6 (Gas6) (Lee et al., 2012b). MerTK is obviously expressed on monocytes, as well as, epithelial and reproductive tissues, and it plays an important role in regulating immune functions such as suppressing the innate immune response and mediating the clearance (efferocytosis) of apoptotic cells (Triantafyllou et al., 2017). It has been reported MerTK that has an inhibitory effect on LPS-induced ALI (Lee et al., 2012a). The phosphatidylinositol 3-hydroxy kinase/protein kinase $\mathrm{B} /$ mammalian target of rapamycin (PI3K/AKT/mTOR) pathway plays an important role in cell growth, proliferation, apoptosis and autophagy as a crucial intracellular signal transduction pathway (Zhang et al., 2016). It has been demonstrated that the inflammatory response induced by LPS was suppressed by the PI3K/AKT/mTOR pathway (Tsukamoto et al., 2008).

Ginsenoside Rg3 (Figure 1A) is a type of steroid compound that is extracted from ginseng, and it is supposed to have antitumor, anti-inflammatory and anti-fatigue activities (Schmidt et al., 2000; Shirasawa et al., 2004). The activity of ginsenoside Rg3 is closely related to pro-inflammatory cytokines [tumor necrosis factor- $\alpha$ (TNF- $\alpha$ ), interleukin- $1 \beta$ (IL-1 $\beta$ ) and interleukin-6 (IL6)], cyclooxygenase-2 (COX-2) and the NF- $\mathrm{B}$ pathway that plays an important role in inflammation (Ethridge et al., 2002). Some studies have reported that ginsenoside $\mathrm{Rg} 3$ has an immune regulatory effect on LPS-induced ALI (Kim et al., 2013), while little is known about the specific mechanism involved, and whether MerTK takes effect during the inflammatory response is not clear. The present study aims to make it clear whether MerTK takes part in the immune regulatory effect of ginsenoside Rg3 in ALI induced by LPS and illuminate the potential mechanism.

\section{MATERIALS AND METHODS}

\section{High-Performance Liquid Chromatography (HPLC)}

High-performance liquid chromatography was employed to assess the purity of ginsenoside Rg3 by using an EChrom2000 DAD data system (Elite, Dalian, China) (Figure 1B).

\section{Animals and Groups Treatments}

Sixty 6- to 8-week-old male wild type (WT) C57Bl/6 mice (weighing 20-25 g) and sixty male $\mathrm{MerTK}^{-/}-\mathrm{C} 57 \mathrm{Bl} / 6$ mice (weighing 20-25 g) were used in the study and were purchased from the Hubei Provincial Center for Disease Control and Prevention (Hubei, China). All of the mice were fed food and water under specific pathogen-free conditions at approximately $24 \pm 1^{\circ} \mathrm{C}$ with a $40-80 \%$ relative humidity. All experiments were carried out in accordance with guidelines from the Laboratory Animal Research Center of Hubei province. This protocol was approved by the Ethical Committee on Animal Research at Huazhong Agricultural University (HZAUMO-2015-12). All efforts were made to minimize the suffering of animals as much as possible.

Ginsenoside Rg3 (purity $\geq 98 \%$ ) was obtained from the Yuanye Biotechnology Company (Shanghai, China). LPS (Escherichia coli 055:B5) was purchased from Sigma (St. Louis, MO, United States). Dexamethasone (DEX) was purchased from Biosharp (Wuhan, China). The method of establishing the LPSinduced ALI model was performed as described previously (Hu et al., 2017). Briefly, $10 \mu \mathrm{g}$ of LPS in $50 \mu \mathrm{L}$ of sterile phosphate buffered saline (PBS) was administered intranasally into the nose to induce ALI. Ginsenoside Rg3 and DEX were intraperitoneally injected $1 \mathrm{~h}$ before LPS treatment. These mice were randomly divided into 8 groups as follows.

$\left(\mathrm{A}_{1}\right)$ Control group (CG): The WT mice were treated with $50 \mu \mathrm{L}$ of PBS.

$\left(\mathrm{A}_{2}\right)$ DEX group (DEX): $1 \mathrm{~h}$ before LPS treatment, the WT mouse model of ALI was intraperitoneally injected with DEX at $5 \mathrm{mg} / \mathrm{kg}$.

$\left(\mathrm{A}_{3}\right)$ Ginsenoside Rg3 group (GG): $1 \mathrm{~h}$ before LPS treatment, the WT mouse model of ALI were intraperitoneally injected with ginsenoside $\mathrm{Rg} 3$ at 30 , 20 , and $10 \mathrm{mg} / \mathrm{kg}$.

$\left(\mathrm{A}_{4}\right)$ LPS group (LPS): The WT mouse model of ALI without drug treatment.

$\left(\mathrm{B}_{1}\right)$ Control group (CG): The $\mathrm{MerTK}^{-/-}$mice were treated with $50 \mu \mathrm{L}$ of PBS.

$\left(\mathrm{B}_{2}\right)$ DEX group (DEX): $1 \mathrm{~h}$ before LPS treatment, the $\mathrm{MerTK}^{-/-}$mouse model of ALI was intraperitoneally injected with DEX at $5 \mathrm{mg} / \mathrm{kg}$.

$\left(B_{3}\right)$ Ginsenoside Rg3 group (GG): $1 \mathrm{~h}$ before LPS treatment, the $\mathrm{MerTK}^{-1-}$ mouse model of ALI was intraperitoneally injected with ginsenoside $\mathrm{Rg} 3$ at 30, 20, and $10 \mathrm{mg} / \mathrm{kg}$.

$\left(\mathrm{B}_{4}\right)$ LPS group (LPS): The MerTK ${ }^{-/-}$mouse model of ALI without drug treatment. 
A

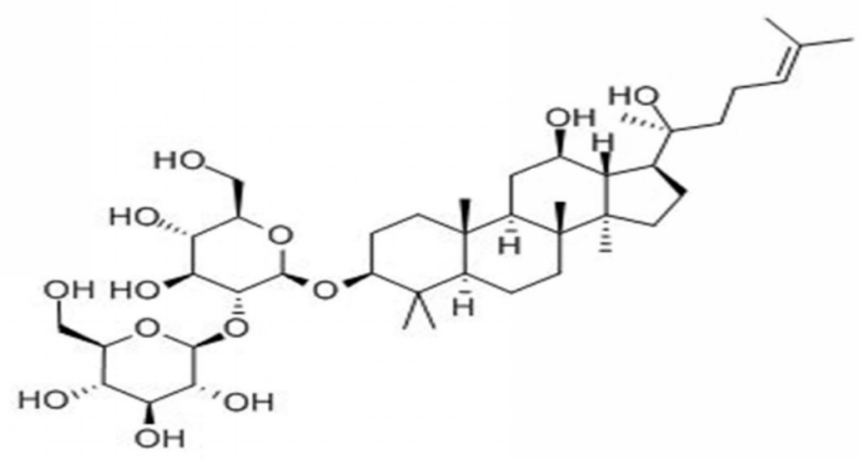

B

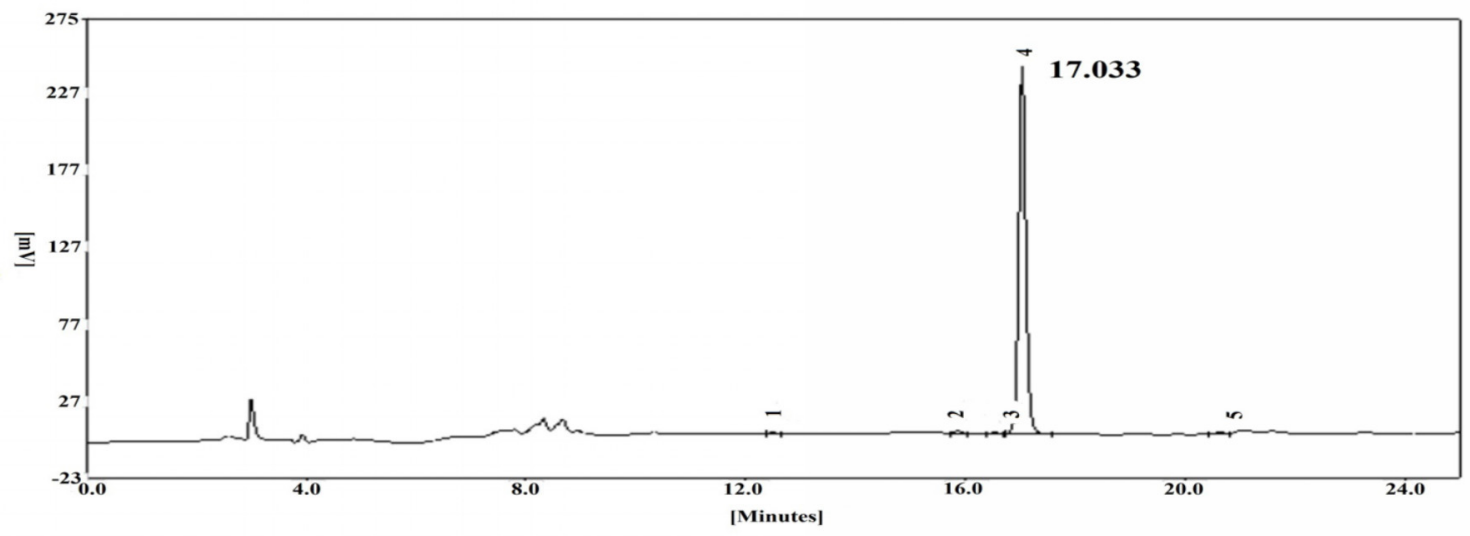

FIGURE 1 | (A) Chemical structure of ginsenoside Rg3. (B) HPLC chromatogram of ginsenoside Rg3.

After treatment, all of the mice were euthanized by inhalation of the $\mathrm{CO}_{2}$. The lung tissues were collected $12 \mathrm{~h}$ after LPS induction, and stored at $-80^{\circ} \mathrm{C}$ until analysis.

\section{Histopathological Evaluation}

Lung tissues were acquired and fixed with $4 \%$ paraformaldehyde for 2 days. Subsequently, individual lobes of tissues biopsy material were placed in processing cassettes, dehydrated in a serial alcohol gradient, embedded in paraffin, and sectioned at a thickness of $4 \mu \mathrm{m}$. The 4 - $\mu \mathrm{m}$-thick lung tissue sections were dewaxed in xylene, rehydrated through decreasing concentrations of ethanol, and washed in PBS. Then the lung tissue sections were stained with hematoxylin and eosin (H\&E), the cell nucleus were stained with hematoxylin and the cytoplasm was stained with eosin. After staining, sections were dehydrated through increasing concentrations of ethanol and xylene, finally the sections were sealed by neutral balsam for further analysis. The histopathological changes were observed with a light microscopy (Olympus, Japan).

\section{Immunofluorescence}

The paraffin sections were repaired with EDTA Buffer and washed with PBS three times. Then the paraffin sections were incubated in $3 \%$ hydrogen peroxide solution at room temperature in the dark for $10 \mathrm{~min}$ to eliminate endogenous peroxidases, and blocked in 5\% BSA for $20 \mathrm{~min}$. The paraffin sections were incubated at $4^{\circ} \mathrm{C}$ overnight with $50 \mu \mathrm{L}$ of primary antibodies against p-MerTK (1:150 dilutions, Bioss, United States). Subsequently, the paraffin sections were incubated with the secondary antibodies (1:50 dilutions, Aspen, China) at $37^{\circ} \mathrm{C}$ for $50 \mathrm{~min}$. After staining, fluorescence microscope coupled with the MicroPublisher imaging software platform (Q-imaging) was used to observe the fluorescence intensity.

\section{MPO Assay}

The lung tissues were harvested $12 \mathrm{~h}$ after LPS stimulated, and the tissues were homogenized with reaction buffer for myeloperoxidase (MPO) levels assay using an MPO commercial sandwich enzyme-linked immunosorbent assay (ELISA) kit (Eton Bioscience, San Diego, CA, United States) according to the manufacturer's instructions. The detailed method is as follows: $100 \mu \mathrm{L}$ of MPO standard solutions and $100 \mu \mathrm{L}$ of samples were added to the proper wells, and then, they were incubated at $37^{\circ} \mathrm{C}$ for $90 \mathrm{~min}$. One hundred microliters of biotinylated anti-mouse MPO antibody working solution was added to each well, and the plate was incubated at $37^{\circ} \mathrm{C}$ for $60 \mathrm{~min}$. Each well was then washed with $100 \mu \mathrm{L}$ of PBS 3 times. Subsequently, avidin-biotinperoxidase complex working solution was added to each well and the plate was incubated at $37^{\circ} \mathrm{C}$ for another $30 \mathrm{~min}$. Finally, $90 \mu \mathrm{L}$ of TMB color developing agent and $100 \mu \mathrm{L}$ of TMB stop 
solution were added to each well, and the absorbance of each well was measured at $450 \mathrm{~nm}$ using a microplate reader (Bio-Rad Instruments, Hercules, CA, United States).

\section{Cell Culture and Treatment}

RAW264.7 cells were acquired from the American Type Culture Collection (ATCC TIB-71 ${ }^{\mathrm{TM}}$ ). The cells were cultured in DMEM supplemented with $10 \%$ FBS and were incubated continually at $37^{\circ} \mathrm{C}$ with $5 \% \mathrm{CO}_{2}$. Ginsenoside $\mathrm{Rg} 3$ was dissolved in dimethyl sulfoxide (DMSO), and then diluted with DMEM to different concentrations for cell experiments. The final concentration of DMSO was less than $0.1 \% \mathrm{v} / \mathrm{v}$. The cells were treated in groups as follows: (1) CG: cells without any treatment; (2) DEX, cells were incubated with DEX (100 $\mu \mathrm{g} / \mathrm{ml})$ as the positive control; (3) GG, cells were incubated with 100,50 , or $25 \mu \mathrm{g} / \mathrm{ml}$ ginsenoside $\mathrm{Rg} 3$ for $1 \mathrm{~h}$, and then, the cells were stimulated by $2 \mu \mathrm{g} / \mathrm{ml}$ LPS for $12 \mathrm{~h}$, and (4) LPS-stimulated group, cells were only stimulated with $2 \mu \mathrm{g} / \mathrm{ml}$ LPS.

\section{Cell Viability Assay}

The cell viability was evaluated with using the MTT assay. RAW264.7 cells were seeded in 96-well plates for $12 \mathrm{~h}$ and then incubated with or without ginsenoside $\operatorname{Rg} 3(25,50$, and $100 \mu \mathrm{g} / \mathrm{mL})$ or DEX $(100 \mu \mathrm{g} / \mathrm{mL})$. After $12 \mathrm{~h}$ of incubation, $20 \mu \mathrm{L}$ of MTT was added into each well. Subsequently, the medium was removed, and $150 \mu \mathrm{L}$ of DMSO was added into 96-well plates, which were agitated on the shaker table for $10 \mathrm{~min}$. The optical density $(O D)$ value was determined at $490 \mathrm{~nm}$ using a microplate reader.

\section{ELISA Assay}

The effect of ginsenoside $\mathrm{Rg} 3$ on the expression levels of pro-inflammatory cytokines and anti-inflammatory cytokines induced by LPS were measured using mouse TNF- $\alpha$, IL- $1 \beta$ and IL-6, interleukin-10 (IL-10) and transforming growth factor- $\beta$ (TGF- $\beta$ ) ELISA kits (BioLegend, United States) according to the manufacturer's protocols. Fifty microliters of a serial dilution gradient standard or sample was added to the appropriate wells and incubated at room temperature for $2 \mathrm{~h}$. Then, the plate was washed 4 times with $1 \times$ wash buffer. Subsequently, $100 \mu \mathrm{L}$ of detection antibody solution was added to each well and incubated at room temperature for $1 \mathrm{~h}$. After washing the plate 4 times with $1 \times$ wash buffer, $100 \mu \mathrm{L}$ of avidin-HRP solution was added to each well and incubated at room temperature for $30 \mathrm{~min}$. One hundred microliters of substrate solution and $100 \mu \mathrm{L}$ of stop solution were added to each well in turn; finally, the $O D$ value was determined at $450 \mathrm{~nm}$ using a microplate reader.

\section{Quantitative Real-Time Polymerase Chain Reaction (qRT-PCR) Assay}

The total RNA was extracted from RAW264.7 cells using Trizol reagent (Transgen Biotech, China) following the manufacturer's protocols. Then, the total RNA ( $1 \mu \mathrm{g})$ was reverse-transcribed to cDNA using the PrimeScript RT Reagent Kit with gDNA Eraser (TaKaRa, Japan). Gene-specific primers for quantitative real-time PCR were designed using Premier 7.0 software (Premier Biosoft
International, Palo Alto, CA, United States), and the primers used are presented in the Table 1. Quantitative real-time PCR was performed on an ABI Stepone Plus real-time PCR instrument using SYBR Green qPCR Master Mix (TaKaRa, Japan). The thermal profile was as follows: $5 \mathrm{~min}$ at $95^{\circ} \mathrm{C}, 40$ cycles of $95^{\circ} \mathrm{C}$ for $30 \mathrm{~s}, 59^{\circ} \mathrm{C}$ for $15 \mathrm{~s}$, and $72^{\circ} \mathrm{C}$ for $20 \mathrm{~s}$. $\beta$-actin was used to normalize all real-time PCR data, and the blank control was set to 1. The relative gene expression was calculated using the $2^{-\Delta \Delta c t}$ computing method.

\section{Flow Cytometry}

The RAW264.7 cells were harvested from a 6-well plate and washed with cold PBS three times. Then, the cells were stained with PE Rat Anti-Mouse F4/80 (565410, BD, United States), FITC Rat Anti-Mouse CD11b (557396, BD, United States), APC-Cy7 Hamster Anti-Mouse CD11c (561241, BD, United States), PECy7 Rat Anti-Mouse CD16/CD32 (560829, BD, United States) and Rat Anti-Mouse CD206 (565250, BD, United States) antibodies at $4^{\circ} \mathrm{C}$ for $30 \mathrm{~min}$. After staining, the cells were washed with PBS three times and resuspended with $100 \mu \mathrm{L}$ of PBS for FACS analysis using a BD FACSAria II instrument (BD, United States). The data were further analyzed using Flowjo software 7.6.

\section{Western Blot Analysis}

The total protein was extracted from lung tissues and RAW264.7 cells using RIPA reagent (Beyotime Biotechnology, China) following the manufacturer's protocols. The protein concentrations were determined using the BCA protein assay kit (Beyotime Biotechnology, China). Equal amounts $(50 \mu \mathrm{g})$ of proteins were separated with $10 \%$ SDS-PAGE. Then, the proteins were transferred to polyvinylidene difluoride (PVDF) membranes, and the PVDF membranes were blocked in $2 \%$ BSA in TBST at room temperature for $2 \mathrm{~h}$. The membranes were incubated at $4^{\circ} \mathrm{C}$ overnight with primary antibodies against PI3K, AKT, mTOR, p-PI3K, p-AKT, p-mTOR, $\beta$-actin (1:1000 dilutions, CST, United States), MerTK and p-MerTK (1:1000 dilutions, Bioss, United States), with $\beta$-actin used as a control.

\begin{tabular}{|c|c|c|c|}
\hline Name & Primer sequence $\left(5^{\prime}-3^{\prime}\right)$ & $\begin{array}{l}\text { GenBank } \\
\text { accession } \\
\text { number }\end{array}$ & $\begin{array}{c}\text { Product } \\
\text { size } \\
\text { (bp) }\end{array}$ \\
\hline $\mathrm{TNF}-\alpha$ & $\begin{array}{l}\text { СССTCACACTCAGATCATCTTCT } \\
\text { GCTACGACGTGGGCTACAG }\end{array}$ & NM_000594.3 & 61 \\
\hline $\mathrm{IL}-1 \beta$ & $\begin{array}{l}\text { CCTGGGCTGTCCTGATGAGAG } \\
\text { TCCACGGGAAAGACACAGGTA }\end{array}$ & NM_008361.4 & 131 \\
\hline IL-6 & $\begin{array}{l}\text { GGCGGATCGGATGTTGTGAT } \\
\text { GGACCCCAGACAATCGGTTG }\end{array}$ & NM_031168.1 & 199 \\
\hline $\mathrm{IL}-10$ & $\begin{array}{l}\text { TTGAATTCCCTGGGTGAGAAG } \\
\text { TCCACTGCCTTGСTCTTATा }\end{array}$ & NM_000572.2 & 95 \\
\hline TGF- $\beta$ & $\begin{array}{l}\text { CTGGATACCAACTACTGCTTCAG } \\
\text { TTGGTTGTAGAGGGCAAGGACCT }\end{array}$ & NM_000660.6 & 198 \\
\hline$\beta$-actin & $\begin{array}{l}\text { ACGGCCAGGTCATCACTATTG } \\
\text { CAAGAAGGAAGGCTGGAAA }\end{array}$ & NM_001101.4 & 71 \\
\hline
\end{tabular}


Subsequently, the membranes were washed with TBST five times and incubated with the secondary antibodies (1:1000 dilutions, Beyotime Biotechnology, China) at room temperature for $1 \mathrm{~h}$. Finally, the protein levels were detected with an ECL Plus Western Blotting Detection System (Image Quant LAS 4000 mini, United States).

\section{Statistical Analysis}

All the values were presented as the mean \pm SEM. One-way ANOVA followed by Dunnet's post hoc test was used for analyzing the differences between groups. A value of $P<0.05$ was defined as statistically significant.

\section{RESULTS}

\section{Anti-inflammatory Effects of Ginsenoside Rg3 in WT Groups}

Lung tissues were harvested $12 \mathrm{~h}$ after LPS induction and then fixed for $\mathrm{H} \& \mathrm{E}$ staining, the results are shown in Figure 2A. In WT mice groups, there were no histological changes in the control group, while the group induced by LPS showed significant histological changes characterized by alveolar structure destruction, hemorrhage and inflammatory cell infiltration. The ginsenoside $\operatorname{Rg} 3$ treatment group significantly improved lung injury, and the DEX treatment group similarly showed significantly less lung injury.

The production of MPO was measured to assess the neutrophil infiltration in the lung tissues in the present study. As is shown in Figure 2B, MPO levels significantly increased in the LPS-stimulated group when compared with the control group. The increases of MPO levels were significantly suppressed by ginsenoside $\mathrm{Rg} 3$.

To assess the cytotoxicity of ginsenoside Rg3 on RAW264.7 cells, the MTT assay was used to measure the cell viability. The results demonstrated that the cell viability was not affected by ginsenoside $\operatorname{Rg} 3$ (Figure 2C). The effects of ginsenoside $\operatorname{Rg} 3$ on the production of cytokines in lung tissues and RAW264.7 cells were measured by an ELISA assay. The results in lung tissues showed that the expression levels of TNF- $\alpha$, IL- $1 \beta$ and IL- 6 were significantly increased after LPS treatment, while the levels of IL-10 and TGF- $\beta$ were significantly decreased. In contrast, the increases of pro-inflammatory cytokines (TNF- $\alpha$, IL-1 $\beta$ and IL-6) were obviously inhibited, and the decreases of anti-inflammatory cytokines (IL-10 and TGF- $\beta$ ) were significantly promoted by ginsenoside Rg3 and DEX (Figure 2D). The same results were observed in the RAW264.7 cell groups (Figure 2E). Likewise, the results of RAW264.7 cells measured by the qRT-PCR assay were consistent with those of the ELISA assays. The mRNA expression levels of TNF- $\alpha$, IL- $1 \beta$ and IL- 6 were significantly increased, and the mRNA expression levels of anti-inflammatory cytokines IL10 and TGF- $\beta$ were decreased after LPS stimulation compared with the control group. In contrast, ginsenoside Rg3 treatment suppressed the increases of pro-inflammatory cytokines (TNF$\alpha$, IL- $1 \beta$ and IL- 6 ) as well as the decreases of anti-inflammatory cytokines (IL-10 and TGF- $\beta$ ) in a dose-dependent manner (Figure 2F).
As an important class of immune cells, murine macrophage RAW264.7 cells, have been widely employed to mimic the inflammatory response to evaluate the curative effect of an antiinflammatory drug in LPS-induced ALI in vitro (Liu et al., 2017; Yang et al., 2017). Thus, we employed RAW264.7 cells to investigate the polarization of activated macrophages. From the results, it could be seen that the ratio of M2/M1 was obviously decreased after LPS treatment compared with the control group. However, in ginsenoside Rg3 treatment groups, the M2/M1 ratios were remarkably increased despite LPS stimulation. These results revealed that ginsenoside $\mathrm{Rg} 3$ treatment may exert an antiinflammatory effect by promoting M2 polarization (Figure 2G).

\section{Effects of Ginsenoside Rg3 Treatment on LPS-Induced Activation of the PI3K/AKT/mTOR Pathway in WT Groups}

The activation of the PI3K/AKT/mTOR pathway induced by LPS was assessed to investigate the specific anti-inflammatory mechanism of ginsenoside Rg3. These results indicated that LPS increased the quantity of the expression of the phosphorylation of PI3K, AKT and mTOR in lung tissues, consistent with previous studies (Ohtani et al., 2008; Mendes Sdos et al., 2009). However, in ginsenoside $\operatorname{Rg} 3$ and DEX treatment groups, the phosphorylation levels of these proteins showed an overall increased trend when compared with the LPS-treatment group (Figure 3A). To further confirm the results presented in lung tissues, the same studies were performed on RAW264.7 cells, and similar results were observed, with only high or medium doses of ginsenosides $\mathrm{Rg} 3$ treatment significantly affecting the level of phosphorylation of these proteins (Figure 3B).

\section{Effects of Ginsenoside Rg3 on MerTK Expression in WT Groups}

To further explore whether MerTK could play a vital role in ginsenoside $\mathrm{Rg} 3$-dependent immunomodulatory effects, we detected the expression levels of the phosphorylation of MerTK in lung tissues of WT mice and RAW264.7 cells. After LPS stimulation, the expression levels of p-MerTK were increased in both lung tissues and RAW264.7 cells. In contrast, p-MerTK protein significantly increased after ginsenoside Rg3 and DEX treatment (Figures 4A,B). Similarly, immunofluorescence was applied to investigate the expression levels of $\mathrm{p}$-MerTK in lung tissues. Compared with the control group, the expression levels of p-MerTK in the LPS-induced group exhibited a significant decrease. Meanwhile, the expression levels of p-MerTK obviously increased in ginsenoside $\mathrm{Rg} 3$ and DEX treatment groups (Figure 4C).

\section{Ginsenoside Rg3 Does Not Have an Anti-inflammatory Effect in MerTK ${ }^{-/-}$ Mice After ALI}

To further confirm whether the anti-inflammatory effects of ginsenoside $\mathrm{Rg} 3$ were mediated through MerTK, MerTK ${ }^{-/-}$ mice were used in the present study. In $\mathrm{MerTK}^{-/}$mice groups, it could be seen that pathological changes did not represent significant differences among LPS stimulated, 


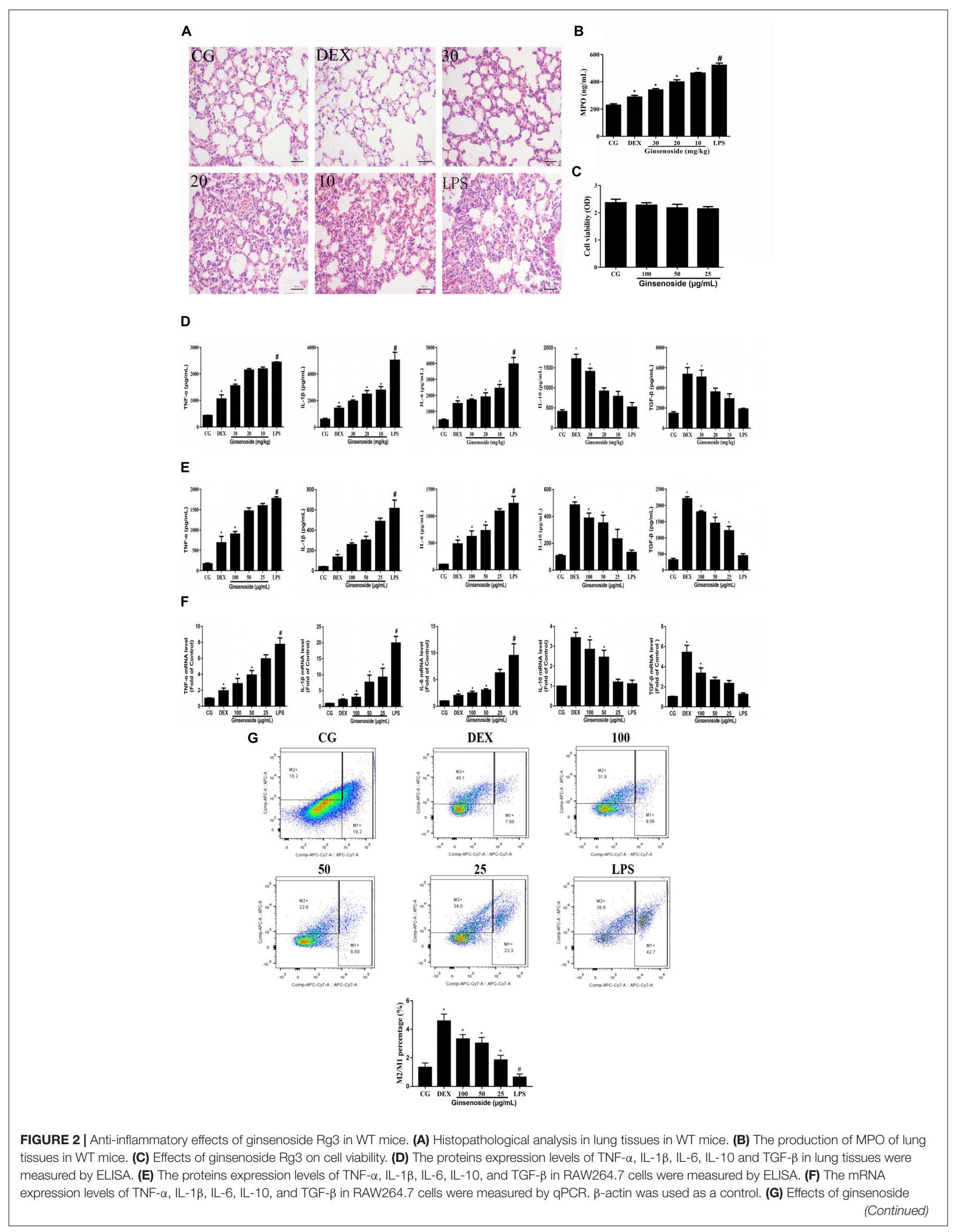


FIGURE 2 | Continued

Rg3 on LPS-induced macrophage polarization in RAW264.7 cells. M1 macrophages were labeled with FITC Rat Anti-Mouse CD11b, PE Rat Anti-Mouse F4/80, APC-Cy7 Hamster Anti-Mouse CD11c and PE-Cy7 Rat Anti-Mouse CD16/CD32 antibodies. M2 macrophages were labeled with PE Rat Anti-Mouse F4/80, FITC Rat Anti-Mouse CD11b and Rat Anti-Mouse CD206 antibodies. The M2/M1 ratio in RAW264.7 cells was analyzed by flow cytometry. Gating was performed on F4/80+ cells. CG is the control group. LPS is the LPS-stimulated group. DEX is the dexamethasone group. Ginsenoside (10, 20, and 30) represent ginsenoside Rg3 $(10,20$, and $30 \mathrm{mg} / \mathrm{kg})+$ LPS in animals and Ginsenoside $(25,50$, and 100) represent ginsenoside Rg3 (25, 50, and 100 $\mu \mathrm{g} / \mathrm{mL})+\mathrm{LPS}$ in cells, respectively. The data are presented as the mean \pm SEM of three independent experiments. ANOVA, $p<0.01$, post hoc \#p $<0.05$ vs. CG. * $p<0.05$ vs. LPS group.

ginsenoside $\operatorname{Rg} 3$ and DEX treatment groups, which still showed severe lung pathological damage (Figure 5A). MPO levels and the production of cytokines in lung tissues of MerTK $^{-/-}$mice also revealed no significant difference between the LPS treatment group and the medicine treatment groups (Figures 5B-D). These aforementioned results indicated that the anti-inflammatory effects of ginsenoside $\mathrm{Rg} 3$ are mediated by MerTK.

\section{PI3K/AKT/mTOR Pathway Activation Is Dependent on MerTK}

To demonstrate whether the effects of ginsenoside $\mathrm{Rg} 3$ attenuating LPS-induced lung injury were mediated by the MerTK-dependent PI3K/AKT/mTOR pathway, MerTK ${ }^{-/-}$mice were used to assess the protein expression levels of the phosphorylation of PI3K, AKT and mTOR. As is shown in
Figure 6, the expression levels of these phosphorylated proteins showed no significant differences among the LPS injection group, ginsenoside Rg3 treatment group and DEX treatment group, while the phosphorylation of these proteins remarkably increased after LPS induction compared with the control group. These results further proved that ginsenoside $\mathrm{Rg} 3$ promotes LPSinduced activation of the PI3K/AKT/mTOR pathway, which is dependent on MerTK.

\section{DISCUSSION}

ALI remains a major problem in clinical disease (Zimmermann et al., 2017), which affects the health of most humans (Rubenfeld et al., 2005). Ginsenoside Rg3, a traditional herbal medicine, is mainly involved in curing lung cancer (Kim et al., 2014). Some
A
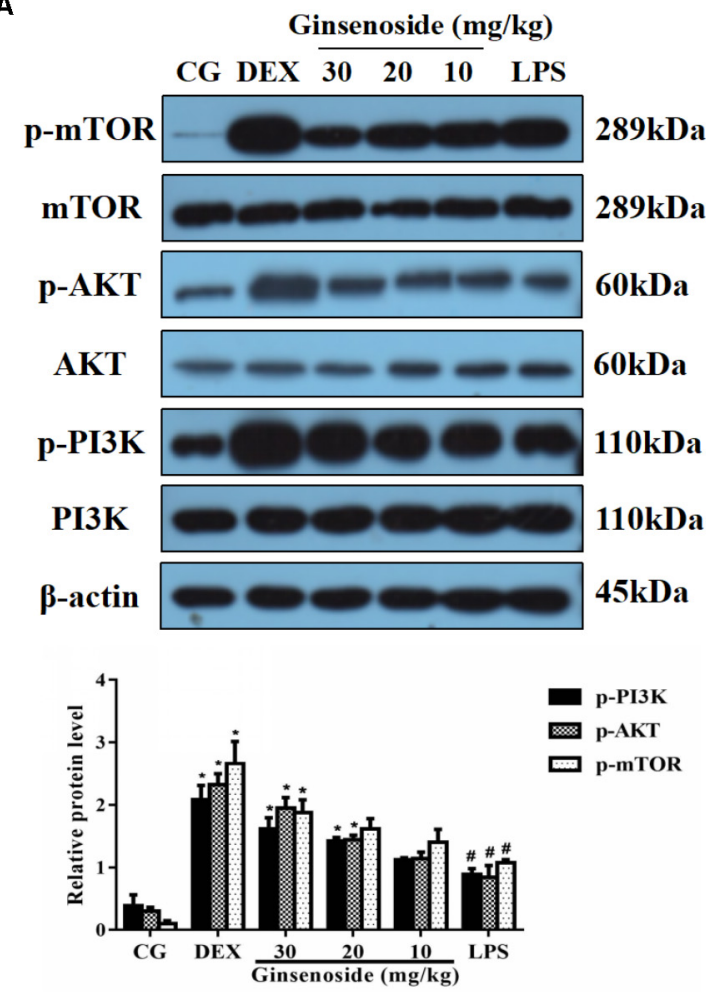

B

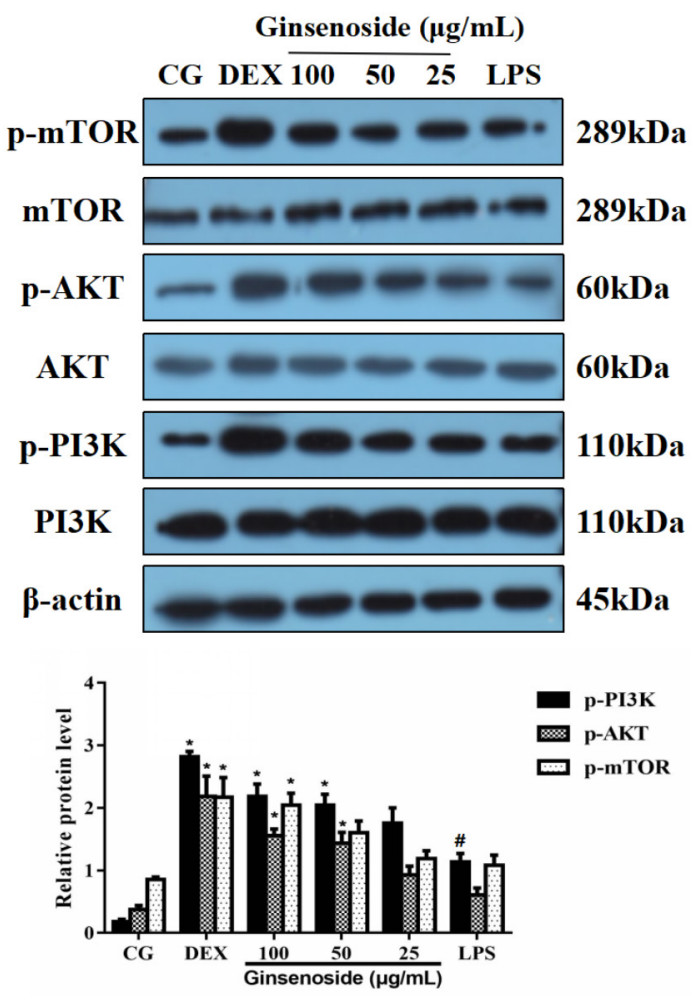

FIGURE 3 | Effects of ginsenoside Rg3 on LPS-induced activation of the PI3K/AKT/mTOR pathway in WT groups. (A) The levels of PI3K, AKT and mTOR proteins in lung tissues were measured by western blotting. (B) The levels of PI3K, AKT and mTOR proteins in RAW264.7 cells were measured by western blotting. $\beta$-actin was used as a control. CG is the control group. LPS is the LPS-stimulated group. DEX is the dexamethasone group. The data are presented as the mean \pm SEM of three independent experiments. ANOVA, $p<0.01$, post hoc $\# p<0.05$ vs. CG. ${ }^{*} p<0.05$ vs. LPS group. 

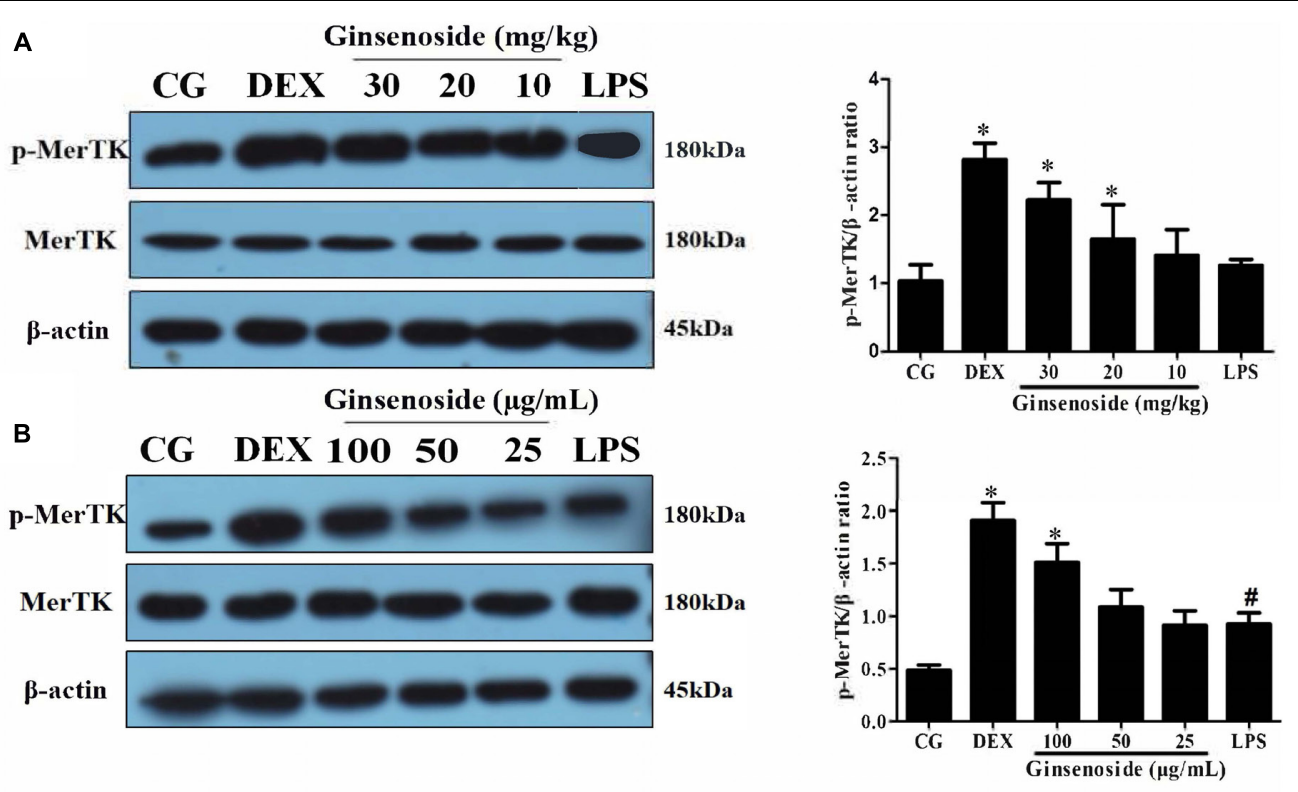

c

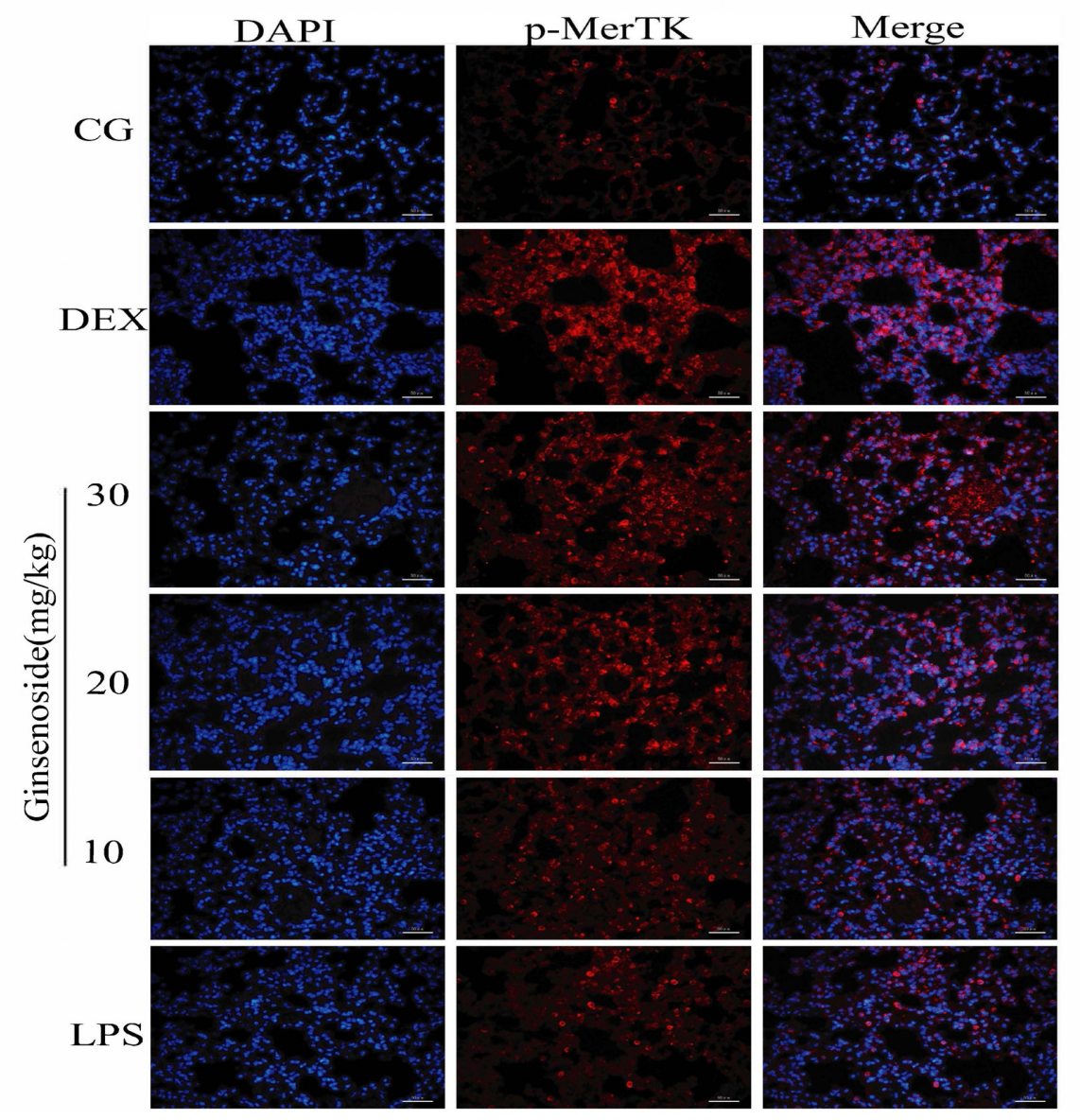

FIGURE 4 | Effects of ginsenoside Rg3 on the expression of MerTK in WT groups. (A) The expression of MerTK protein in lung tissues was measured by western blotting. (B) The expression of MerTK protein in RAW264.7 cells was measured by western blotting. (C) The expression of MerTK protein in lung tissues was measured by immunofluorescence. p-MerTK protein was labeled with a red fluorophore, and the cell nucleus was labeled with a blue fluorophore. CG is the control group. LPS is the LPS-stimulated group. DEX is the dexamethasone group. Ginsenoside (10, 20, and 30) represent ginsenoside Rg3 (10, 20, and 30mg/kg) + LPS in animals and Ginsenoside (25, 50, and 100) represent ginsenoside Rg3 (25, 50, and $100 \mu \mathrm{g} / \mathrm{mL})+$ LPS in cells. The data are presented as the mean \pm SEM of three independent experiments. ANOVA, $p<0.05$, post hoc ${ }^{\#} p<0.05$ vs. CG. ${ }^{*} p<0.05$ vs. LPS group. 

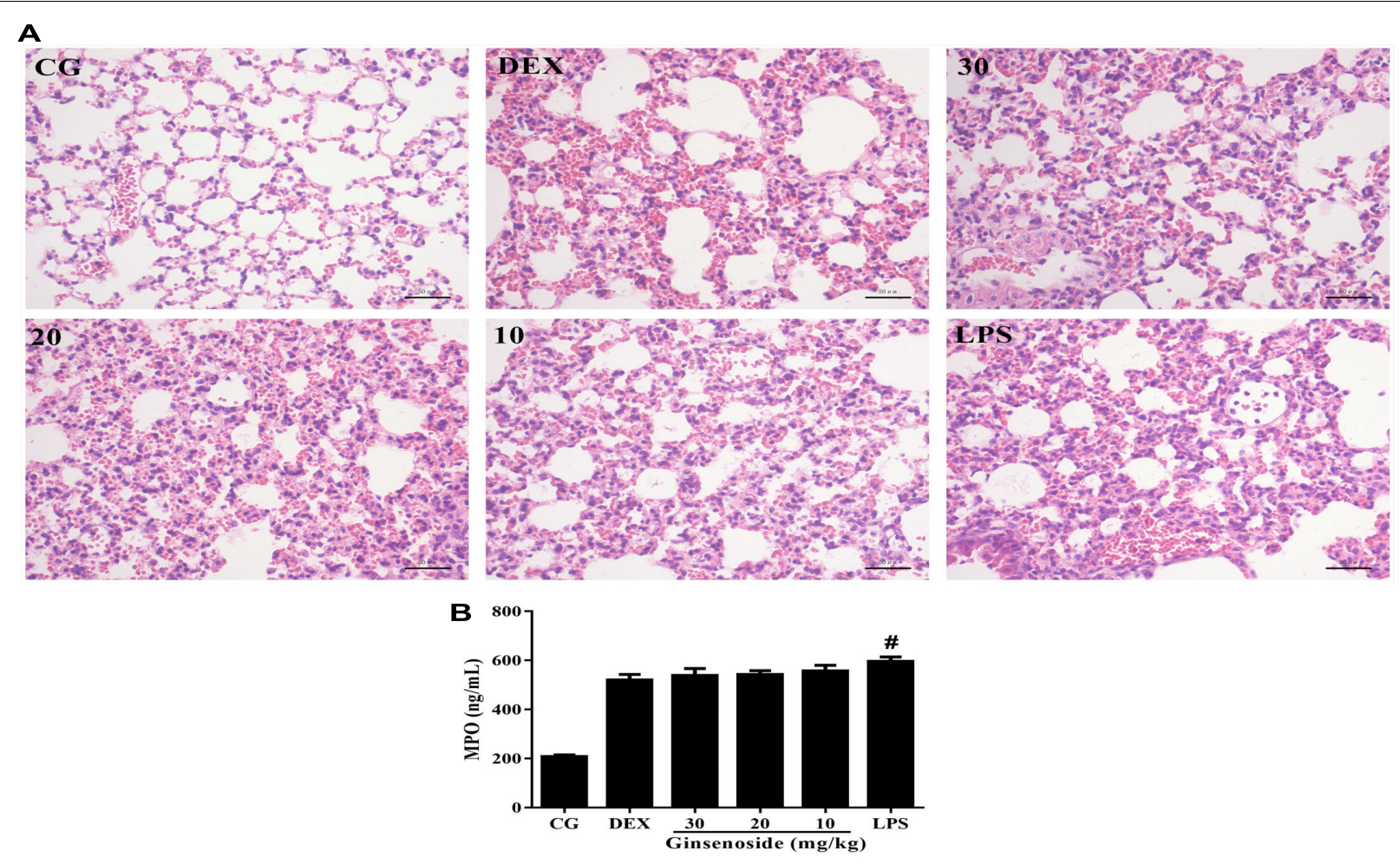

C
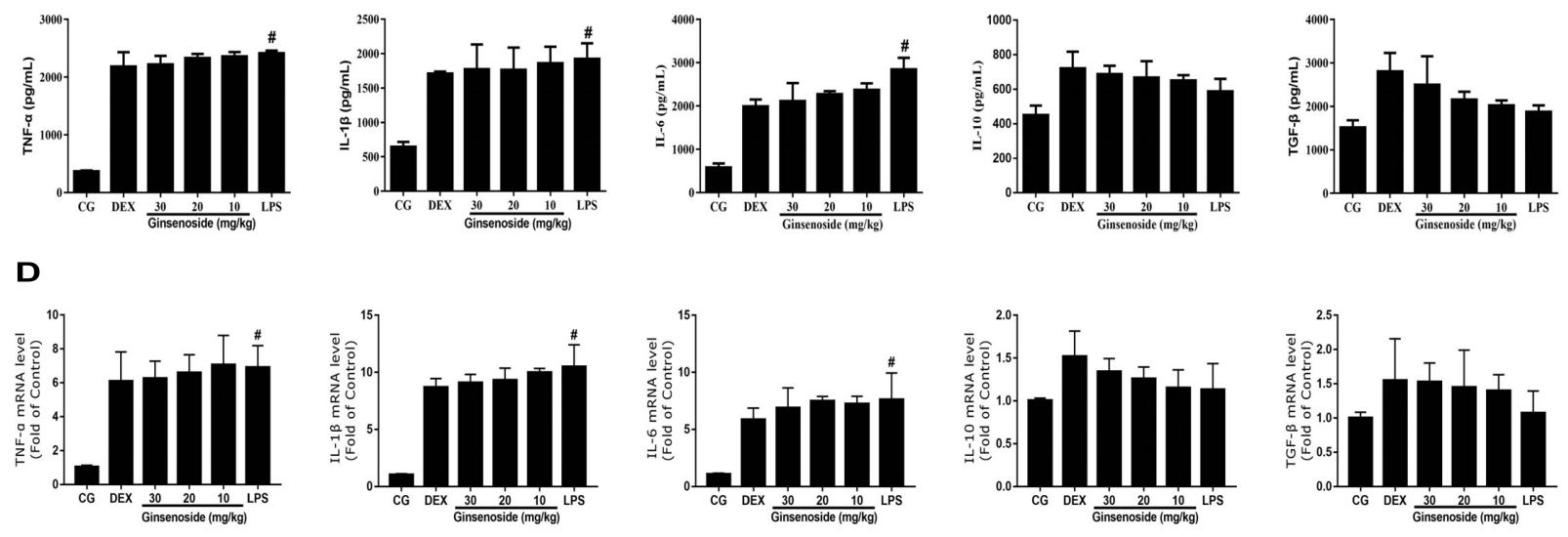

FIGURE 5 | Anti-inflammatory effects of ginsenoside Rg3 in MerTK ${ }^{-/-}$mice. (A) Histopathological analysis of lung tissues in MerTK ${ }^{-/-}$mice. (B) The production of MPO in lung tissues in MerTK ${ }^{-/-}$mice. (C) The protein expression levels of TNF- $\alpha, \mathrm{IL}-1 \beta, \mathrm{IL}-6$, IL-10, and TGF- $\beta$ in lung tissues of MerTK- - mice were measured by ELISA. (D) The mRNA expression levels of TNF- $\alpha, \mathrm{IL}-1 \beta, \mathrm{IL}-6, \mathrm{IL}-10$, and TGF- $\beta$ in lung tissues of MerTK $-/-$ mice were measured by qPCR. $\beta$-actin was used as a control. CG is the control group. LPS is the LPS-stimulated group. DEX is the dexamethasone group. Ginsenoside (10, 20, and 30) represent ginsenoside Rg3 (10, 20 , and $30 \mathrm{mg} / \mathrm{kg})+$ LPS in animals. The data are presented as the mean \pm SEM of three independent experiments. ANOVA, $p<0.01, p 0 s t$ hoc $\# p<0.05$ vs. CG.

recent research has verified that ginsenoside $\operatorname{Rg} 3$ is supposed to have anti-tumor, anti-inflammatory and anti-fatigue activities (Bi et al., 2017; Guan and Xu, 2017). However, research with regards to the specific mechanism by which ginsenoside $\mathrm{Rg} 3$ takes effect on the anti-inflammatory process is rarely reported. In the present study, we established a mouse model of ALI to explore the possible mechanism of ginsenoside Rg3 in the inflammatory response induced by LPS.

In the present study, we demonstrated that ginsenoside Rg3 exerted an anti-inflammatory function, consistent with a previous study (Hien et al., 2010). We found that ginsenoside Rg3 treatment could relieve inflammation despite serious lung pathological damage induced by LPS according to the histological results. MPO is mainly synthesized and expressed by neutrophils (Sabharwal et al., 1995), and it is widely considered to be the main symbol of neutrophil activation and recruitment in inflammatory reaction (Klebanoff, 2005; Jiang et al., 2017). Some studies have suggested that the levels of MPO could be regarded as an indicator of increased risk for local and systemic inflammation (Nizam et al., 2014; Wang et al., 2014). 

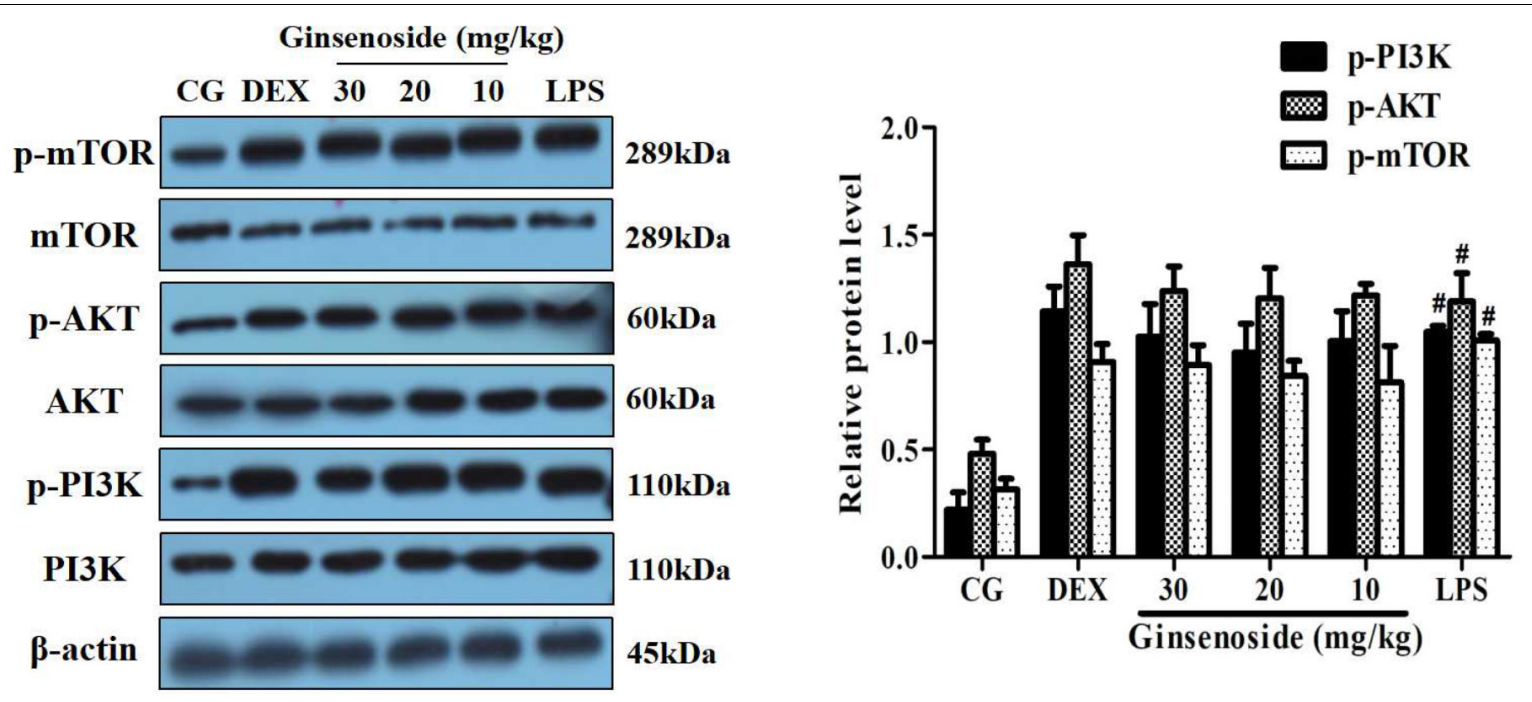

FIGURE 6 | Effects of ginsenoside Rg3 on the LPS-induced activation of the PI3K/AKT/mTOR pathway in MerTK ${ }^{-/-}$mice. The levels of PI3K, AKT and mTOR proteins in lung tissues were measured by western blotting. CG is the control group. LPS is the LPS-stimulated group. DEX is the dexamethasone group. Ginsenoside (10, 20, and 30) represent ginsenoside Rg3 (10, 20, and $30 \mathrm{mg} / \mathrm{kg})+\mathrm{LPS}$ in animals. The data are presented as the mean \pm SEM of three independent experiments. ANOVA, $p<0.01$, post hoc ${ }^{\#} p<0.05$ vs. CG.

As it is shown by the results, the production of MPO was obviously increased after LPS stimulation, which was consistent with previous studies (Menghini et al., 2016; Locatelli et al., 2017). Ginsenoside Rg3 treatment could dose-dependently decrease the production of MPO in lung tissues, indicating that ginsenoside Rg3 could interpose neutrophil activation and recruitment after LPS challenge.

Neutrophils and macrophages, which play a major role in the inflammatory response in LPS-induced ALI, are the primary source of diversified inflammatory mediators such as pro-inflammatory cytokines TNF- $\alpha$, IL- $1 \beta$ and IL- 6 as well as anti-inflammatory cytokines IL-10 and TGF- $\beta$ (Goodman et al., 2003; Fligiel et al., 2006). In the study presented here, we found that ginsenoside Rg3 significantly inhibited the increases of the pro-inflammatory cytokines TNF- $\alpha$, IL- $1 \beta$ and IL- 6 as well as prevented the decreases of anti-inflammatory cytokines IL-10 and TGF- $\beta$ after LPS stimulation. The process by which macrophage activation induced different subtypes to respond to changes in the environment is generally called polarization, and the phenotype of polarization can be divided into M1 and M2 (Xie et al., 2016). The polarization of M2 macrophages appears to promote the release of anti-inflammatory and immunosuppressive agents as well as motivate the repair and healing of damaged tissue (Arnold et al., 2007; Kang et al., 2008). Intriguingly, ginsenoside $\mathrm{Rg} 3$ treatment also led to an increase in LPS-induced M2 polarization. Taken together, ginsenoside Rg3 exerted anti-inflammatory action through decreasing the production of pro-inflammatory cytokines, increasing the expression levels of anti-inflammatory mediators and promoting M2 polarization.

The PI3K/AKT/mTOR signaling pathway is involved in the antitumor effects of ginsenoside $\mathrm{Rg} 3$ in lung cancer cells (Xie et al., 2017). Ginsenoside Rg3 inhibits angiogenesis in a rat model of endometriosis through the VEGFR-2-mediated PI3K/Akt/mTOR signaling pathway (Cao et al., 2017). Recent studies also have revealed that activation of the PI3K/AKT pathway exhibits a protective effect in a mouse model of ALI. However, there is no report on whether ginsenoside Rg3 can attenuate LPS-induced ALI via the PI3K/Akt/mTOR signaling pathway. In our study, ginsenoside $\mathrm{Rg} 3$ treatment increased the expression of phosphorylated PI3K, AKT and mTOR in LPS-challenged mice. PI3K/Akt has been shown to suppress the activation of NF- $\kappa \mathrm{B}$, which eventually prevents the occurrence of inflammation. NF- $\kappa \mathrm{B}$ is a multifunctional nuclear transcriptional factor, which can regulate a series of cell survival and apoptosis related gene products (Chen et al., 1999). The synthese of pro-inflammatory cytokines TNF- $\alpha$, IL-1 $\beta$, IL6 and IL- 8 are mediated by NF- $\kappa$ B, and these pro-inflammatory cytokines are upregulated by $N F-\kappa B$ transcriptional activity (Tak and Firestein, 2001; Koh et al., 2017). It has been well established that ginsenoside $\mathrm{Rg} 3$ can mitigate inflammation via the NF- $\kappa \mathrm{B}$ pathway (Lee et al., 2016). Interestingly, Ginsenoside Rg3 has also been reported to ameliorate ALI through inactivating the NF- $\mathrm{B}$ signaling pathway (Cheng and Li, 2016). A previous study has demonstrated that mTOR acts downstream of the PI3K/AKT pathway and restrains the effects of NF- $\kappa$ B in LPS-induced RAW264.7 macrophages (Mendes Sdos et al., 2009). Furthermore, the PI3K/AKT/mTOR pathway positively regulates the production of IL-10 (Ohtani et al., 2008), which is thought to be a pleiotropy anti-inflammatory mediator (Zigmond et al., 2014). Thus, the results may be explained by the fact that the $\mathrm{PI} 3 \mathrm{~K} / \mathrm{AKT} / \mathrm{mTOR}$ pathway is activated by ginsenoside Rg3 and then downregulates NF- $\kappa$ B to restrain the transcription of pro-inflammatory mediators as well as upregulates the production of anti-inflammatory cytokines. 
The recent studies have indicated that MerTK has a negative regulatory effect on the LPS-induced the inflammatory response (Lee et al., 2012a). It has been reported that $88.2 \%$ of MerTK $^{-/-}$mice die of releasing excess TNF$\alpha$ due to LPS stimulation (Camenisch et al., 1999), and RAW264.7 cells treated with the anti-MerTK antibody enhancing the production of inflammatory cytokines (Lee et al., 2012a). More importantly, MerTK plays a critical role in the activation of PI3K/Akt. There is growing evidence that MerTK mediates the activation of PI3K/Akt pathway in macrophages, and then results in the blockade of NF- $\kappa \mathrm{B}$ (Eken et al., 2010). Stimulation of Mer pathway by Gas6 in U937 cells also gives rise to an increased phosphorylation of Akt (Alciato et al., 2010). In addition, activation of MerTK negatively regulates TLR2-mediated immune response via PI3K/Akt pathway and SOCS3 protein (Zhang et al., 2016). To further explore the specific molecular mechanism through which ginsenoside $\mathrm{Rg} 3$ exerts its anti-inflammatory effect, we measured the MerTK-dependent PI3K/AKT/mTOR signaling pathway. In our study, the expression levels of phosphorylated MerTK significantly increased after ginsenoside Rg3 treatment in both the immunofluorescence and western blot results. Furthermore, the results in $\mathrm{MerTK}^{-/-}$mice showed the same pathological damage, the production of MPO and inflammatory cytokines, whether for the LPS treatment group or ginsenoside $\mathrm{Rg} 3$ treatment groups, and there is no significant difference with regards to the protein expression levels of phosphorylated PI3K, AKT and mTOR between the LPS treatment group and ginsenoside Rg3 treatment groups. These results potently suggest that the anti-inflammatory effects of ginsenoside $\mathrm{Rg} 3$ were

\section{REFERENCES}

Alciato, F., Sainaghi, P. P., Sola, D., Castello, L., and Avanzi, G. C. (2010). TNF-alpha, IL-6, and IL-1 expression is inhibited by GAS6 in monocytes/macrophages. J. Leukoc. Biol. 87, 869-875. doi: 10.1189/jlb.0909610

Arnold, L., Henry, A., Poron, F., Baba-Amer, Y., van Rooijen, N., Plonquet, A., et al. (2007). Inflammatory monocytes recruited after skeletal muscle injury switch into antiinflammatory macrophages to support myogenesis. J. Exp. Med. 204, 1057-1069. doi: 10.1084/jem.20070075

Bi, L., Yan, X., Yang, Y., Qian, L., Tian, Y., Mao, J. H., et al. (2017). The component formula of Salvia miltiorrhiza and Panax ginseng induces apoptosis and inhibits cell invasion and migration through targeting PTEN in lung cancer cells. Oncotarget 8, 101599-101613. doi: 10.18632/oncotarget.21354

Camenisch, T. D., Koller, B. H., Earp, H. S., and Matsushima, G. K. (1999). A novel receptor tyrosine kinase, Mer, inhibits TNF-alpha production and lipopolysaccharide-induced endotoxic shock. J. Immunol. 162, 3498-3503.

Cao, Y., Ye, Q., Zhuang, M., Xie, S., Zhong, R., Cui, J., et al. (2017). Ginsenoside $\mathrm{Rg} 3$ inhibits angiogenesis in a rat model of endometriosis through the VEGFR2-mediated PI3K/Akt/mTOR signaling pathway. PLoS One 12:e0186520. doi: 10.1371/journal.pone.0186520

Chen, F., Castranova, V., Shi, X., and Demers, L. M. (1999). New insights into the role of nuclear factor-kappaB, a ubiquitous transcription factor in the initiation of diseases. Clin. Chem. 45, 7-17.

Chen, X., Tang, L., Feng, J., Wang, Y., Han, Z., and Meng, J. (2017). Downregulation of Paralemmin-3 ameliorates lipopolysaccharide-induced acute lung injury in rats by regulating inflammatory response and inhibiting formation of TLR4/MyD88 and TLR4/TRIF Complexes. Inflammation 40, 1983-1999. doi: 10.1007/s10753-017-0639-9 mediated via the MerTK-dependent PI3K/AKT/mTOR signaling pathway.

\section{CONCLUSION}

The present study demonstrated that ginsenoside Rg3 could attenuate LPS-induced ALI, and the possible molecular mechanism of the protective effects of ginsenoside Rg3 in ALI is probably because of the regulatory effect of MerTK-mediated activation of its downstream PI3K/AKT/mTOR pathway. Our findings may provide further understanding with regards to the anti-inflammatory effects of ginsenoside $\mathrm{Rg} 3$, which may be a potentially powerful drug to cure LPS-induced ALI.

\section{AUTHOR CONTRIBUTIONS}

RF conceived and designed the study. JY drafted the manuscript. JY, SL, LW, FD, XZ, QS, and JZ performed the experiments and analyzed the data. All authors read and approved the final manuscript.

\section{ACKNOWLEDGMENTS}

This work was supported by the Natural Science Foundation of Hubei Province (Grant No. 2017CFA020), Da Bei Nong Group Promoted Project for Young Scholar of HZAU (Grant No. 2017DBN001), and the Science and Technology Development Fund of Tianjin Agricultural University (Grant No. 2014N10).

Cheng, Z., and Li, L. (2016). Ginsenoside Rg3 ameliorates lipopolysaccharideinduced acute lung injury in mice through inactivating the nuclear factorkappaB (NF-kappaB) signaling pathway. Int. Immunopharmacol. 34, 53-59. doi: 10.1016/j.intimp.2016.02.011

Eken, C., Martin, P. J., Sadallah, S., Treves, S., Schaller, M., and Schifferli, J. A. (2010). Ectosomes released by polymorphonuclear neutrophils induce a MerTK-dependent anti-inflammatory pathway in macrophages. J. Biol. Chem. 285, 39914-39921. doi: 10.1074/jbc.M110.126748

Ethridge, R. T., Chung, D. H., Slogoff, M., Ehlers, R. A., Hellmich, M. R., Rajaraman, S., et al. (2002). Cyclooxygenase-2 gene disruption attenuates the severity of acute pancreatitis and pancreatitis-associated lung injury. Gastroenterology 123, 1311-1322. doi: 10.1053/gast.2002. 35951

Ferguson, N. D., Frutos-Vivar, F., Esteban, A., Fernandez-Segoviano, P., Aramburu, J. A., Najera, L., et al. (2005). Acute respiratory distress syndrome: underrecognition by clinicians and diagnostic accuracy of three clinical definitions. Crit. Care Med 33, 2228-2234. doi: 10.1097/01.CCM.0000181529. 08630.49

Fligiel, S. E., Standiford, T., Fligiel, H. M., Tashkin, D., Strieter, R. M., Warner, R. L., et al. (2006). Matrix metalloproteinases and matrix metalloproteinase inhibitors in acute lung injury. Hum. Pathol. 37, 422-430. doi: 10.1016/j.humpath.2005. 11.023

Geissmann, F., Gordon, S., Hume, D. A., Mowat, A. M., and Randolph, G. J. (2010). Unravelling mononuclear phagocyte heterogeneity. Nat. Rev. Immunol. 10, 453-460. doi: 10.1038/nri2784

Goodman, R. B., Pugin, J., Lee, J. S., and Matthay, M. A. (2003). Cytokine-mediated inflammation in acute lung injury. Cytokine Growth Factor Rev. 14, 523-535. doi: 10.1016/S1359-6101(03)00059-5 
Guan, S., and Xu, W. (2017). Ginsenoside Rg1 attenuates cigarette smokeinduced pulmonary epithelial-mesenchymal transition via inhibition of the TGF-betal/Smad Pathway. Biomed Res. Int. 2017:7171404. doi: 10.1155/2017/ 7171404

Hien, T. T., Kim, N. D., Kim, H. S., and Kang, K. W. (2010). Ginsenoside Rg3 inhibits tumor necrosis factor-alpha-induced expression of cell adhesion molecules in human endothelial cells. Pharmazie 65, 699-701.

Hu, X. Y., Tian, Y., Qu, S. H., Cao, Y. G., Li, S. M., Zhang, W. L., et al. (2017). Protective effect of TM6 on LPS-induced acute lung injury in mice. Sci. Rep. 7:572. doi: 10.1038/s41598-017-00551-8

Jiang, K., Ma, X., Guo, S., Zhang, T., Zhao, G., Wu, H., et al. (2017), Anti-inflammatory effects of rosmarinic acid in lipopolysaccharide-induced mastitis in mice. Inflammation 41, 437-448. doi: 10.1007/s10753-0170700-8

Kang, K., Reilly, S. M., Karabacak, V., Gangl, M. R., Fitzgerald, K., Hatano, B., et al. (2008). Adipocyte-derived Th2 cytokines and myeloid PPARdelta regulate macrophage polarization and insulin sensitivity. Cell Metab. 7, 485-495. doi: 10.1016/j.cmet.2008.04.002

Kim, G. D., Oh, J., Park, H. J., Bae, K., and Lee, S. K. (2013). Magnolol inhibits angiogenesis by regulating ROS-mediated apoptosis and the PI3K/AKT/mTOR signaling pathway in $\mathrm{mES} / \mathrm{EB}$-derived endothelial-like cells. Int. J. Oncol. 43, 600-610. doi: 10.3892/ijo.2013.1959

Kim, Y. J., Choi, W. I., Jeon, B. N., Choi, K. C., Kim, K., Kim, T. J., et al. (2014). Stereospecific effects of ginsenoside 20-Rg3 inhibits TGF-beta1-induced epithelial-mesenchymal transition and suppresses lung cancer migration, invasion and anoikis resistance. Toxicology 322, 23-33. doi: 10.1016/j.tox.2014. 04.002

Klebanoff, S. J. (2005). Myeloperoxidase: friend and foe. J. Leukoc. Biol. 77, 598-625. doi: 10.1189/jlb.1204697

Koh, W., Shin, J. S., Lee, J., Lee, I. H., Lee, S. K., Ha, I. H., et al. (2017). Antiinflammatory effect of Cortex Eucommiae via modulation of the toll-like receptor 4 pathway in lipopolysaccharide-stimulated RAW 264.7 macrophages. J. Ethnopharmacol. 209, 255-263. doi: 10.1016/j.jep.2017.08.001

Lee, I. S., Uh, I., Kim, K. S., Kim, K. H., Park, J., Kim, Y., et al. (2016). AntiInflammatory Effects of Ginsenoside Rg3 via NF-kappaB Pathway in A549 Cells and Human Asthmatic Lung Tissue. J. Immunol. Res. 2016:7521601. doi: $10.1155 / 2016 / 7521601$

Lee, Y. J., Han, J. Y., Byun, J., Park, H. J., Park, E. M., Chong, Y. H., et al. (2012a). Inhibiting Mer receptor tyrosine kinase suppresses STAT1, SOCS1/3, and NFkappaB activation and enhances inflammatory responses in lipopolysaccharideinduced acute lung injury. J. Leukoc. Biol. 91, 921-932. doi: 10.1189/jlb. 0611289

Lee, Y. J., Lee, S. H., Youn, Y. S., Choi, J. Y., Song, K. S., Cho, M. S., et al. (2012b). Preventing cleavage of Mer promotes efferocytosis and suppresses acute lung injury in bleomycin treated mice. Toxicol. Appl. Pharmacol. 263, 61-72. doi: 10.1016/j.taap.2012.05.024

Liu, Q., Ci, X., Wen, Z., and Peng, L. (2017). Diosmetin alleviates lipopolysaccharide-induced acute lung injury through activating the Nrf2 pathway and inhibiting the NLRP3 inflammasome. Biomol. Ther. 26, 157-166. doi: 10.4062/biomolther.2016.234

Locatelli, M., Ferrante, C., Carradori, S., Secci, D., Leporini, L., Chiavaroli, A., et al. (2017). Optimization of aqueous extraction and biological activity of harpagophytum procumbens root on ex vivo rat colon inflammatory model. Phytother. Res. 31, 937-944. doi: 10.1002/ptr.5821

Martinez, F. O., Helming, L., and Gordon, S. (2009). Alternative activation of macrophages: an immunologic functional perspective. Annu. Rev. Immunol. 27, 451-483. doi: 10.1146/annurev.immunol.021908.132532

Mendes Sdos, S., Candi, A., Vansteenbrugge, M., Pignon, M. R., Bult, H., Boudjeltia, K. Z., et al. (2009). Microarray analyses of the effects of NF-kappaB or PI3K pathway inhibitors on the LPS-induced gene expression profile in RAW264.7 cells: synergistic effects of rapamycin on LPS-induced MMP9-overexpression. Cell. Signal. 21, 1109-1122. doi: 10.1016/j.cellsig.2009.02.025

Menghini, L., Ferrante, C., Leporini, L., Recinella, L., Chiavaroli, A., Leone, S., et al. (2016). An hydroalcoholic chamomile extract modulates inflammatory and immune response in HT29 cells and isolated rat colon. Phytother. Res. 30, 1513-1518. doi: 10.1002/ptr.5655

Mills, C. D. (2012). M1 and M2 macrophages: oracles of health and disease. Crit. Rev. Immunol. 32, 463-488. doi: 10.1615/CritRevImmunol.v32.i6.10
Niu, X. F., Wang, Y., Li, W. F., Mu, Q. L., Li, H. N., Yao, H., et al. (2015). Protective effects of Isofraxidin against lipopolysaccharide-induced acute lung injury in mice. Int. Immunopharmacol. 24, 432-439. doi: 10.1016/j.intimp.2014.12.041

Nizam, N., Gumus, P., Pitkanen, J., Tervahartiala, T., Sorsa, T., and Buduneli, N. (2014). Serum and salivary matrix metalloproteinases, neutrophil elastase, myeloperoxidase in patients with chronic or aggressive periodontitis. Inflammation 37, 1771-1778. doi: 10.1007/s10753-014-9907-0

Ohtani, M., Nagai, S., Kondo, S., Mizuno, S., Nakamura, K., Tanabe, M., et al. (2008). Mammalian target of rapamycin and glycogen synthase kinase 3 differentially regulate lipopolysaccharide-induced interleukin-12 production in dendritic cells. Blood 112, 635-643. doi: 10.1182/blood-2008-02137430

Rubenfeld, G. D., Caldwell, E., Peabody, E., Weaver, J., Martin, D. P., Neff, M., et al. (2005). Incidence and outcomes of acute lung injury. N. Engl. J. Med. 353, 1685-1693. doi: 10.1056/NEJMoa050333

Sabharwal, A. K., Bajaj, S. P., Ameri, A., Tricomi, S. M., Hyers, T. M., Dahms, T. E., et al. (1995). Tissue factor pathway inhibitor and von Willebrand factor antigen levels in adult respiratory distress syndrome and in a primate model of sepsis. Am. J. Respir. Crit. Care Med. 151(3 Pt 1), 758-767. doi: 10.1164/ajrccm/151.3_ Pt_1.758

Schmidt, A. M., Yan, S. D., Yan, S. F., and Stern, D. M. (2000). The biology of the receptor for advanced glycation end products and its ligands. Biochim. Biophys. Acta 1498, 99-111. doi: 10.1016/S0167-4889(00)00087-2

Shirasawa, M., Fujiwara, N., Hirabayashi, S., Ohno, H., Iida, J., Makita, K., et al. (2004). Receptor for advanced glycation end-products is a marker of type I lung alveolar cells. Genes Cells 9, 165-174. doi: 10.1111/j.1365-2443.2004. 00712.x

Sorgi, C. A., Zarini, S., Martin, S. A., Sanchez, R. L., Scandiuzzi, R. F., Gijon, M. A., et al. (2017). Dormant 5-lipoxygenase in inflammatory macrophages is triggered by exogenous arachidonic acid. Sci. Rep. 7:10981. doi: 10.1038/ s41598-017-11496-3

Tak, P. P., and Firestein, G. S. (2001). NF-kappaB: a key role in inflammatory diseases. J. Clin. Invest. 107, 7-11. doi: 10.1172/JCI11830

Triantafyllou, E., Pop, O. T., Possamai, L. A., Wilhelm, A., Liaskou, E., Singanayagam, A., et al. (2017). MerTK expressing hepatic macrophages promote the resolution of inflammation in acute liver failure. Gut 67, 333-347. doi: 10.1136/gutjnl-2016-313615

Tsukamoto, K., Hazeki, K., Hoshi, M., Nigorikawa, K., Inoue, N., Sasaki, T., et al. (2008). Critical roles of the p110 beta subtype of phosphoinositide 3-kinase in lipopolysaccharide-induced Akt activation and negative regulation of nitrite production in RAW 264.7 cells. J. Immunol. 180, 2054-2061. doi: 10.4049/ jimmunol.180.4.2054

Wang, W., Jian, Z., Guo, J., and Ning, X. (2014). Increased levels of serum myeloperoxidase in patients with active rheumatoid arthritis. Life Sci. 117, 19-23. doi: 10.1016/j.lfs.2014.09.012

Xie, J., Wu, X., Zhou, Q., Yang, Y., Tian, Y., Huang, C., et al. (2016). PICK1 confers anti-inflammatory effects in acute liver injury via suppressing M1 macrophage polarization. Biochimie 127, 121-132. doi: 10.1016/j.biochi.2016.05.002

Xie, Q., Wen, H., Zhang, Q., Zhou, W., Lin, X., Xie, D., et al. (2017). Inhibiting PI3K-AKt signaling pathway is involved in antitumor effects of ginsenoside Rg3 in lung cancer cell. Biomed. Pharmacother. 85, 16-21. doi: 10.1016/j.biopha. 2016.11.096

Yang, S., Yu, Z., Wang, L., Yuan, T., Wang, X., Zhang, X., et al. (2017). The natural product bergenin ameliorates lipopolysaccharide-induced acute lung injury by inhibiting NF-kappaB activition. J. Ethnopharmacol. 200, 147-155. doi: 10.1016/j.jep.2017.02.013

Zhang, B., Fang, L., Wu, H. M., Ding, P. S., Xu, K., and Liu, R. Y. (2016). Mer receptor tyrosine kinase negatively regulates lipoteichoic acid-induced inflammatory response via PI3K/Akt and SOCS3. Mol. Immunol. 76, 98-107. doi: 10.1016/j.molimm.2016.06.016

Zhu, G., Xin, X., Liu, Y., Huang, Y., Li, K., and Wu, C. (2017). Geraniin attenuates LPS-induced acute lung injury via inhibiting NF-kappaB and activating Nrf2 signaling pathways. Oncotarget 8, 22835-22841. doi: 10.18632/oncotarget. 15227

Zigmond, E., Bernshtein, B., Friedlander, G., Walker, C. R., Yona, S., Kim, K. W., et al. (2014). Macrophage-restricted interleukin-10 receptor deficiency, but not IL-10 deficiency, causes severe spontaneous colitis. Immunity 40, 720-733. doi: 10.1016/j.immuni.2014.03.012 
Zimmermann, K. K., Spassov, S. G., Strosing, K. M., Ihle, P. M., Engelstaedter, H., Hoetzel, A., et al. (2017). Hydrogen Sulfide Exerts Anti-oxidative and Antiinflammatory Effects in Acute Lung Injury. Inflammation 41, 249-259. doi: 10.1007/s10753-017-0684-4

Conflict of Interest Statement: The authors declare that the research was conducted in the absence of any commercial or financial relationships that could be construed as a potential conflict of interest.
Copyright (c) 2018 Yang, Li, Wang, Du, Zhou, Song, Zhao and Fang. This is an open-access article distributed under the terms of the Creative Commons Attribution License (CC BY). The use, distribution or reproduction in other forums is permitted, provided the original author(s) and the copyright owner(s) are credited and that the original publication in this journal is cited, in accordance with accepted academic practice. No use, distribution or reproduction is permitted which does not comply with these terms. 